\title{
Claudia Hofmann
}

\section{Internationale Sozialstandards im nationalen Recht}

Eine Untersuchung am Beispiel des Systems sozialer Sicherheit in Südafrika

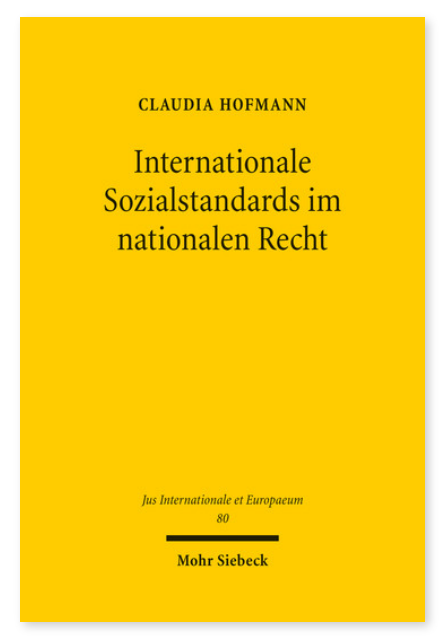

2013. XIX, 318 Seiten. JusIntEu 80

ISBN 978-3-16-152384-7

DOI 10.1628/978-3-16-152384-7

eBook PDF 94,00€

ISBN 978-3-16-152383-0

fadengeheftete Broschur 94,00€
Seit Gründung der Internationalen Arbeitsorganisation wurde im internationalen öffentlichen Recht eine Vielzahl von bindenden wie nicht bindenden - Normen geschaffen, die auf die Aufrechterhaltung, vor allem aber die Verbesserung der sozioökonomischen Lebenssituation des Einzelnen abzielen. Claudia Hofmann untersucht anhand des südafrikanischen Systems sozialer Sicherheit, welchen Einfluss diese internationalen Sozialstandards im nationalen Rechtssystem haben. Sie verknüpft dazu rechts- und politikwissenschaftliche Perspektiven und geht folgenden Fragen nach: Welche Inhalte internationaler Sozialstandards werden in der südafrikanischen sozialrechtlichen Gesetzgebung und Rechtsprechung rezipiert? Welches sind die zentralen Akteure und relevanten rechtlichen Strukturen in diesem »Einflussprozess«? Welche Theorien beziehungsweise Theorieansätze gibt es im Hinblick auf diesen Prozess?

Claudia Hofmann Geboren 1977; Studium der Rechtswissenschaft an der Ludwig-Maximilians-Universität München; 2012 Promotion (Kassel); 2018 Habilitation (Regensburg), seit 2020 Inhaberin des Lehrstuhls für Öffentliches Recht und Europäisches Sozialrecht mit Schwerpunkt in der interdisziplinären Sozialrechtsforschung an der Europa-Universität Viadrina Frankfurt (Oder).
Jetzt bestellen:

https://mohrsiebeck.com/buch/internationale-sozialstandards-im-nationalen-recht-9783161523847?no_cache=1 order@mohrsiebeck.com

Telefon: +49 (0)7071-923-17

Telefax: $+49(0) 7071-51104$ 